\title{
Perceived stress, quality of life, and coping skills among patients with schizophrenia in symptomatic remission
}

\author{
Sheikh Shoib', Soumitra Das ${ }^{2}$, Anoop Krishna Gupta ${ }^{3}$,Tamkeen Saleem ${ }^{4}$ and Sheikh Mohd Saleem ${ }^{5^{*}}$ (1)
}

\begin{abstract}
Background: Schizophrenia is one of the worst diseases with its ubiquitous challenges due to its unique psychopathology and life events. Patients with schizophrenia use various coping strategies to overcome distress. The aim of the study was to evaluate the association between perceived stress, quality of life, and coping skills in patients with schizophrenia in remission. A total of 48 consecutive patients of schizophrenia, in remission, attending outpatient department of psychiatry at Academic hospital, South India, who satisfied the inclusion and exclusion criteria were recruited for the present study. The participants were assessed on Positive and Negative Symptoms Scale, Ways of Coping Checklist - Revised and Perceived Stress Scale and WHO Quality of Life. Results were analyzed using appropriate statistical package software $v$ 16.0.

Result: Highest medial was found in self-controlling and positive reappraisal coping skills. Distancing is associated with high physical domain of quality of life whereas patients with good social support score more in social and physical domain of quality of life.

Conclusion: Patients with history of schizophrenia even though in remission dwell a stressful life. They often need different kind of social support or cognitive aids. In that view, studying their stress level, ability to cope with it, and quality of life will help us to manage them in better way.
\end{abstract}

Keywords: Stress, Coping skills, Quality of life, Schizophrenia, Remission

\section{Background}

Schizophrenia is one of the most difficult diseases to treat because of its distinct psychopathology and life events [1]. Patients with schizophrenia have incapacitating symptoms, impaired social functioning, difficulties in daily life activities, a lack of motivation, deteriorated communication skills, and social cohesion, and available treatments often provide only limited benefits $[2,3]$. These symptoms interfere with the patient's educational, occupational, familial, and social functioning [4].

The concept of remission in schizophrenia has garnered attention since it is significant and necessary for

\footnotetext{
*Correspondence: saleem.900@gmail.com

${ }^{5}$ Independent Health Consultant, J\&K, Srinagar, India

Full list of author information is available at the end of the article
}

patients' functional improvement [5]. The term "remission" has a significant connotation for patients and, as a result, has nonstop implications for their well-being. Remission is defined as a period of 6 months or more in which a patient with schizophrenia has no or only minor symptoms of schizophrenia [6].

There are contradictory findings in the literature; nonetheless, a few studies show that social functioning and quality of life are better in schizophrenia patients during remission than in schizophrenia patients who are not in remission $[2,7,8]$. However, some other research found the quality-of-life outcomes in schizophrenia patients in symptomatic remission to be debatable $[9,10]$.

Patients with schizophrenia employ a variety of coping methods to cope with their uncomfortable symptoms as well as their regular life activities and stressors 
[11]. According to studies, persons with schizophrenia frequently engage in avoidance or distraction, drug use, and social seclusion in order to cope with symptoms and control their suffering [12]. To deal with stressful events, they frequently employ "emotion-focused" and "passive coping" tactics. They frequently avoid confronting pressures rather than considering potential solutions [13].

According to one study, patients with schizophrenia typically utilize the coping strategy of seeking social support, which is followed by "accepting and daydreaming" and "active and growth-oriented coping." The findings also revealed that those who employed "active and growth-oriented coping" more frequently had fewer negative symptoms, a lower level of disability, and a higher quality of life [14]. Many researchers have also found that patients frequently employ "help seeking" or "seeking social support" to cope with psychotic, non-psychotic symptoms, and day-to-day life pressures $[15,16]$.

Psychiatrists in India are relieved by the absence of psychotic symptoms in patients with schizophrenia during routine out-patient assessments in frantic psychiatric clinics. However, their interior experiences, such as perceived stress and coping, are rarely measured. Lack of sleep [17], mastery [18], family support [19], and less use of atypical antipsychotics [20] have all been linked to poor quality of life in schizophrenia patients. Coping styles, among other things, have been linked to general QOL [21]. According to a recent Asian study, personal empowerment was the best predictor of QOL in schizophrenia [22]. Both positive and negative coping mechanisms were found to be strongly associated to QOL [23]. The objective standard of life, on the other hand, does not guarantee good QOL [24]. Though the stress-vulnerability-coping model has been implicated in earlier western studies [25], such a model has not been discovered on the Indian subcontinent.

As a result, the current study sought to examine perceived stress, quality of life, and coping abilities in schizophrenia patients in symptomatic remission. Also, this study tried to explore the relationship between perceived stress and quality of life, duration of illness and coping skills, age group and coping styles, etc. We hypothesized that positive coping styles would improve quality of life in different domains, which might be seen more in younger group with shorter duration of illness.

\section{Methods}

\section{Study design}

It was a hospital-based cross sectional study conducted between January 2018 and September 2019 in Academic hospital, South India.

\section{Sample}

Every patient with the diagnosis of schizophrenia was screened for remission within the study period. After meeting the inclusion and exclusion criteria, 48 patients from the outpatient Department of Psychiatry were included in the sample. Outpatients with a diagnosis of schizophrenia who were in remission (clinical and functional) and aged 18 to 65 years old met the inclusion criteria. Exclusion criteria included patients with full-blown symptomatology of schizophrenia, schizophrenia in remission accompanied by substance use (excluding nicotine), post-schizophrenic depression, and patients unable to participate in the trial due to a major medical ailment. The study comprised patients of both genders, between the ages of 18 and 65, with a DCR-10 diagnosis of schizophrenia and in remission (Clinical and Functional). Patients with a concomitant drug use disorder (excluding nicotine) or schizoaffective disorder who were physically unfit or reluctant to give consent were excluded from the trial. Written consent was obtained from all participants in the current study; also, the research ethics committee at the Government T.D Medical College, Alappuzha approved the study.

\section{Study instruments}

Researchers carried out the assessment using a set of standardized evaluation procedures after receiving proper training in the administration and scoring of all study instruments. In the current study, the Diagnostic Criteria for Research Accompanying the ICD-10 (DCR10) were utilized for the diagnosis of patients with schizophrenia in asymptomatic remission (WHO 1992).

\section{Definition of remission}

When a patient with schizophrenia is asymptomatic or has low levels of psychopathology for at least 6 months, they are said to be in clinical remission. Additionally, the Positive and Negative Syndrome Scale [PANSS], a 30-item, 7-point (1-7) rating scale, was used to ensure remission. The PANSS (positive and negative symptoms scale) score of 3 on items $1-3$ of the positive subscale; 1,4 , and 6 of the negative subscales; and 5 and 9 of the general psychopathologies' subscales were deemed to indicate low severity of symptoms or clinical remission [26]. The Personal and Social Performance Scale (PSP) was used to assess functioning [27]. The PSP is a singleitem rating scale with a total of 100 points divided into ten equal intervals. The ratings are primarily based on an evaluation of the patient's functioning in four areas: (1) socially helpful activities, (2) personal and social interactions, (3) self-care, and (4) unsettling and aggressive 
behaviors. A total score of 80 or greater implies a state of "functional remission." Internal consistency reliability (alpha $=0.76)$ was adequate.

\section{Quality of life}

WHO QOL-BREF was used to assess quality of life. The WHO QOL-BREF consists of 26 questions in total. To provide a broad and complete assessment, one item from each of the WHO QOL-100's 24 components has been included. In addition, two elements from the aspect of Overall Quality of Life and General Health have been incorporated [28].

\section{Coping styles}

The revised Ways of Coping Checklist (WCC), which consists of 66 items measuring cognitive and behavioral strategies for coping with stressful experiences, was utilized. Confrontive coping, distancing, self-controlling, seeking social support, accepting responsibility, escapeavoidance, planful issue solving, and positive reappraisal are the coping subscales evaluated on a 4-point scale. The sum of the item scores yields the score on each subscale. With a Cronbach's alpha value of 0.89 , this checklist is highly reliable [29].

\section{Stress scale}

The Perceived Stress Scale (PSS) developed by Cohen, Kamarck, and Mermelstein [30] consisting of 14 items $(0=$ never; $1=$ almost never; $2=$ sometimes; $3=$ fairly often; $4=$ very often) was used. Scores $0-18$ show that there is low stress, $19-37$ moderate stress, and 38-56 high perceived stress. The reliability of the scale is $r=.78$ [30].

For this study, all the scales were translated into Malayalam using the World Health Organization's translation approach of translation-back-translation. This was done to make use of this particular questionnaire, more meaningful in our context where a large portion of the population is predominantly Malayalam speaking.

\section{Data collection process/procedure}

The study was explained to patients and relatives, and signed informed consent was obtained in each case. A complete history, general examination, systemic physical examination, mental status examination, necessary laboratory tests, and psychometric evaluation were performed on all participants. Psycho-socio-demographic and other clinical characteristics were obtained for each subject by completing a specifically constructed proforma. The DCR-10 criteria were used to make the diagnosis. A consultant from the Department of Psychiatry reviewed each case and verified the diagnosis.
Because 48 patients met the inclusion and exclusion criteria, 48 people were chosen as the study sample. The WHO Quality of Life [WHOQOL] questionnaire was then administered to the subjects, followed by the Ways of Coping Checklist - Revised (WCC) to measure the repertoire of coping abilities. These scales were specifically applied to each subject. During the trial, there was no interference with the patients' treatment. Additionally, PANSS and PSP scales were used to ensure remission and functioning respectively. All findings were documented in a particular proforma for the present study.

\section{Statistical analysis}

Data was entered in a Microsoft Excel spreadsheet. Continuous variables were summarized as mean and standard deviation. Categorical variables were summarized as percentages. Chi-square test was used to test independence between two categorical variables. Spearman correlation was computed to assess the relationship between perceived stress and domains of quality of life. MannWhitney $U$ test was used to compare differences between two independent groups of patients. A $p$ value of less than 0.05 was considered statistically significant. All statistical analysis was done using SPSS 16.0.

\section{Results}

Socio-demographic and clinical profile of patients is described in Table 1. Majority of the patients were male and of age 40 or above, educated up to intermediate level. Most of them were unemployed from rural background belonging to lower socioeconomic status. Most of them were married and stayed in nuclear families. The age of onset was more than 20 years. Onsets of illness in majority of the study subjects were between 21 and 40 years. The duration of illness in majority of the study subjects were up to $20( \pm 11)$ years. Table 2 indicates correlation between Ways of Coping and Quality of Life (QOL) among the patients of schizophrenia in asymptomatic remission. Findings revealed that distancing and seeking social support were positively related with G1 (Physical Domain) of QOL. Spearman correlation was computed to assess the relationship between perceived stress and domains of quality of life in patients of schizophrenia in asymptomatic remission. Table 3 reveals that there is a significant negative relationship of perceived stress with physical health and social relationships. The results are significant at the level of 0.05 . The results also indicate that there is a trend of negative relationship of perceived stress with psychological health and environment. However, the findings were not statistically significant.

Mann-Whitney $U$ test was used to compare differences between two independent groups of patients of schizophrenia in remission based on duration of illness. 
Table 1 Sociodemographic status of studied population

\begin{tabular}{|c|c|c|c|}
\hline Age & Male & Female & Total \\
\hline Below 40 & 8 & 13 & 21 \\
\hline 40 and above & 19 & 8 & 27 \\
\hline Total & 27 & 21 & 48 \\
\hline \multirow[t]{5}{*}{ Education } & Education & $F$ & $\%$ \\
\hline & Illiterate and primary & 17 & 35.4 \\
\hline & Middle, high, and intermediate & 22 & 45.8 \\
\hline & Graduate, post graduate, professional & 9 & 18.8 \\
\hline & Total & 48 & 100 \\
\hline \multirow[t]{6}{*}{ Marital status } & Marital status & $F$ & $\%$ \\
\hline & Single & 12 & 25.0 \\
\hline & Married & 33 & 68.8 \\
\hline & Separated & 1 & 2.1 \\
\hline & Divorced & 2 & 4.2 \\
\hline & Total & 48 & 100.0 \\
\hline \multirow[t]{4}{*}{ Socio economic status } & Socio economic status & $F$ & $\%$ \\
\hline & Upper and middle & 16 & 33.3 \\
\hline & Lower & 32 & 66.7 \\
\hline & Total & 48 & 100 \\
\hline \multirow[t]{4}{*}{ Duration of illness } & Duration of illness & $F$ & $\%$ \\
\hline & Up to 20 years & 33 & 68.8 \\
\hline & 21 to 40 years & 15 & 31.2 \\
\hline & Total & 48 & 100.0 \\
\hline \multirow[t]{4}{*}{ Age of onset } & Age of onset & $F$ & $\%$ \\
\hline & Up to 20 years & 14 & 29.2 \\
\hline & 21 to 40 years & 34 & 70.8 \\
\hline & Total & 48 & 100.0 \\
\hline
\end{tabular}

Table 2 Spearman correlation between Ways of Coping Checklist—Revised (WCC) and Quality of Life (WHOQOL-BREF)

\begin{tabular}{|c|c|c|c|c|c|c|c|c|}
\hline & \multicolumn{8}{|l|}{ WCC } \\
\hline & $\begin{array}{l}\text { Confrontive } \\
\text { coping }\end{array}$ & Distancing & Self-controlling & $\begin{array}{l}\text { Seeking } \\
\text { social } \\
\text { support }\end{array}$ & $\begin{array}{l}\text { Accepting } \\
\text { responsibility }\end{array}$ & $\begin{array}{l}\text { Escape } \\
\text { avoidance }\end{array}$ & $\begin{array}{l}\text { Planful } \\
\text { problem } \\
\text { solving }\end{array}$ & $\begin{array}{l}\text { Positive } \\
\text { reappraisal }\end{array}$ \\
\hline \multicolumn{9}{|l|}{ WHO-BRIF } \\
\hline $\begin{array}{l}\text { WHOQOL- } \\
\text { BREF physical } \\
\text { health }\end{array}$ & $.147(.311)$ & $.512(.000)$ & $.219(.135)$ & $656(.000)$ & $306(.053)$ & $-.036(.808)$ & $.147(.711)$ & $.147(.371)$ \\
\hline $\begin{array}{l}\text { WHOQOL- } \\
\text { BREF psychologi- } \\
\text { cal health }\end{array}$ & $.077(.601)$ & $566(.709)$ & $542(.601)$ & $.339(.711)$ & $.240(.101)$ & $.056(.736)$ & $496(.312)$ & $.372(.312)$ \\
\hline $\begin{array}{l}\text { WHOQOL- } \\
\text { BREF social } \\
\text { relationships }\end{array}$ & $.024(0.871)$ & $317(082)$ & .643 .530 & $628(.000)$ & $231(.114)$ & .055 (.709) & $0.595(.652)$ & $.489(.512)$ \\
\hline $\begin{array}{l}\text { WHOQOL- } \\
\text { BREF environ- } \\
\text { ment }\end{array}$ & $.053(.721)$ & $540(.316)$ & $.579(.231)$ & $.383(007)$ & $.267(.66)$ & $.109(.461)$ & $51.8(.407)$ & $.418(.503)$ \\
\hline
\end{tabular}

The findings in Table 4 indicate that the patients with the duration of illness up to 20 years had usage of self-controlling, accepting responsibility, and planful problem solving as coping skill strategies. The findings were statistically significantly higher than the patient's group with the duration of illness of 21 to 40 years. However, the 
Table 3 Spearman correlation between Perceived Stress Scale (PSS) and quality of life (QoL)

\begin{tabular}{lll}
\hline QOL facets* PSS & $\begin{array}{l}\text { Perceived Stress } \\
\text { Scale }\end{array}$ & $\boldsymbol{p}$ value \\
\hline WHOQOL-BREFd physical health & -.318 & $0.01^{*}$ \\
WHOQOL-BREF psychological health & -.257 & 0.08 \\
WHOQOL-BREF social relationships & -.464 & $0.01^{*}$ \\
WHOQOL-BREF environment & .025 & 0.08 \\
\hline
\end{tabular}

${ }^{*} p$ value $<0.05$ significant

Table 4 Mann-Whitney $U$ test for duration of illness (DUI) and "ways of coping in patients of schizophrenia with symptomatic remission"

\begin{tabular}{llll}
\hline Scales & \multicolumn{2}{l}{ Mean rank (DUI) } & p value \\
\cline { 2 - 3 } & Up to 20years & $\mathbf{2 1 \text { to } 4 0 \text { years }}$ \\
\hline Confrontive coping & 25.23 & 22.90 & .54 \\
Distancing & 26.56 & 19.97 & .11 \\
Self-controlling & $\mathbf{2 7 . 5 8}$ & $\mathbf{1 7 . 7 3}$ & $\mathbf{. 0 1 *}$ \\
Seeking social support & 26.64 & 19.80 & .11 \\
Accepting responsibility & $\mathbf{2 8 . 0 5}$ & $\mathbf{1 6 . 7 0}$ & $\mathbf{. 0 1 *}$ \\
Escape-avoidance & $\mathbf{2 3 . 2 3}$ & $\mathbf{2 7 . 3 0}$ & $\mathbf{. 0 5 *}$ \\
Planful problem-solving & $\mathbf{2 7 . 8 0}$ & $\mathbf{1 7 . 2 3}$ & $\mathbf{. 0 1 *}$ \\
Positive reappraisal & 25.91 & 21.40 & .27 \\
\hline
\end{tabular}

${ }^{*} p$ value $<0.05$ significant

Table 5 Mann-Whitney $U$ test for "age-groups" and "ways of coping in patients of schizophrenia with asymptomatic remission"

\begin{tabular}{llll}
\hline WCC & \multicolumn{2}{l}{ Mean rank } & p value \\
\cline { 2 - 3 } & Age below 40 & $\begin{array}{l}\text { Age 40 and } \\
\text { above }\end{array}$ & \\
\hline Confrontive coping & 24.69 & 24.35 & .92 \\
Distancing & 26.9 & 22.63 & .27 \\
Self-controlling & 28.36 & 21.50 & .08 \\
Seeking social support & 27.95 & 21.81 & .12 \\
Accepting responsibility & $\mathbf{2 9 . 1 7}$ & $\mathbf{2 0 . 8 7}$ & $\mathbf{. 0 2}$ \\
Escape-avoidance & 22.5 & 26.06 & .06 \\
Planful problem-solving & $\mathbf{2 9 . 3 3}$ & $\mathbf{2 0 . 7 4}$ & $\mathbf{. 0 2 *}$ \\
Positive reappraisal & 27.31 & 22.31 & .19 \\
\hline
\end{tabular}

${ }^{* *} p$ value $<0.05$ significant

other group with the duration of illness of 21 to 40 years had involvement of escape-avoidance as a coping skill. The results were significant $(p<0.05)$. Mann-Whitney $U$ test was used to compare differences between two independent groups of patients of schizophrenia in asymptomatic remission based on age, i.e., below 40 and above 40 years of age as shown in Table 5 . The findings indicate
Table 6 Median and interquartile (IQ) range of Ways of Coping Checklist (WCC)

\begin{tabular}{lll}
\hline Scale & Median & $\begin{array}{l}\text { Inter } \\
\text { quartile } \\
\text { range }\end{array}$ \\
\hline Confrontive coping & 0 & $0-1$ \\
Distancing & 17 & $11-18$ \\
Self-controlling & 20 & $15-21$ \\
Seeking social support & 12 & $10-14$ \\
Accepting responsibility & 12 & $8.25-12$ \\
Escape-avoidance & 0 & 0 \\
Planful problem-solving & 17.5 & $12-18$ \\
Positive reappraisal & 20 & $18-21$ \\
\hline
\end{tabular}

that the patients with the age below 40 years had usage of accepting responsibility and planful problem solving as coping skill strategies. The findings were significantly higher than the patient's group with the age above 40 years. The results are significant at $p<0.05$. There were non-significant differences between the groups on confrontive coping, distancing, self-controlling, seeking social support, escaping avoidance, and positive reappraisal. Table 6 describes the highest median and interquartile (IQ) range of Ways of Coping Checklist (WCC). It was found that the highest medial was found in selfcontrolling and positive reappraisal coping skills next to planful problem-solving in patients of schizophrenia in asymptomatic remission.

\section{Discussion}

This is the first study to use the stress-vulnerability-coping model on Indian patients with schizophrenia. Previous Indian research have focused solely on QOL [31, 32]. Grover et al. [33] investigated religiosity and spirituality as coping mechanisms. The majority of Indian studies on coping have been undertaken on carers rather than patients [33-36]. This underscores the neglect of the latter demographic in Indian research, despite the fact that they have been extensively studied in the west. Because most patients are expected to achieve remission and live a long life as a result of contemporary medicines and rehabilitation programs, it is sensible to address the quality of their lives [37]. Because the majority of these patients are of average intellect, understanding their coping mechanisms can be beneficial during psychotherapeutic sessions.

The sociodemographic profile has been similar with findings from previous Indian and Asian studies on schizophrenia [22, 33, 35].

Schizophrenia is a severe mental disorder that has a terrible impact on both the patient and his or her family. 
This is because the condition is chronic and frequently causes long-term disability. Positive symptoms such as aggressive behavior, delusions, and hallucinations cause problems for patients, as do negative symptoms such as low motivation and inadequate self-care [38]. The potential for social relationships is frequently decreased, as are career options. Modern treatment methods have assisted a huge number of patients in controlling positive symptoms and greatly improving, but many continue to exhibit deficiencies in numerous areas of functioning [20]. As a result, persistent mental illness places a significant strain on the patient, his or her family, and the community.

Distancing, seeking social support, accepting responsibility, and positive reappraisal have all been proven to aid in stress management, as have prior studies [39]. Seeking social support affected both the physical and social dimensions of QOL. Indian society has recently seen a shift from extended-joint families to nuclear families, which may have been caused by migration, acculturation, and modernity [40]. Seeking social skills in such a situation might be tough. In rural India, the traditional concept of extended families may be the norm, and hence, a study comparing different societal strata may reveal variances in coping techniques. Distancing was discovered to be crucial in maintaining physical QOL. According to the findings of this study, perceived stress has a detrimental and significant impact on physical, psychological, and social domains. Similarly, in a Spanish study, perceived stress was found to mediate poor QOL in schizophrenic individuals [41]. Furthermore, QOL in schizophrenia patients is lower when compared to health controls, which may worsen the situation [41]. As a result, its evaluation becomes critical in day-to-day clinic practice. This may also explain the significance of strengthening clinician skills in reducing perceived stress, as demonstrated in a Korean study [42]. Only local interventional studies could determine whether such an application would improve QOL.

Quality of life and coping techniques appear to be inextricably linked. Utilizing negative coping methods was connected with a lower quality of life, whereas using positive coping strategies was associated with a higher quality of life [23]. In this study, both types of coping techniques were adopted by asymptomatic patients, dispelling the prevalent idea that psychopathology is the primary determinant of QOL. The adoption of positive and negative coping mechanisms is also linked to a subjective assessment of the severity of the illness. According to Ritsner MS et al. [21], 62.2\% of patients' coping patterns stayed stable over time, $19.6 \%$ of patients' coping patterns became unfavorable, and $18.2 \%$ of patients' coping patterns became favorable. Each temporal coping type is associated with a distinct pattern of clinical and psychosocial variable changes. Schizophrenia patients utilize a variety of coping strategies to alleviate their distress. Controlling for intake symptom severity and impairments in adaptive coping (acceptance, planning, and seeking help) predicted a proportionate increase in schizophrenia symptoms over time.

Coping refers to a person's continually shifting cognitive and behavioral efforts to manage a stressful encounter. Problem-solving methods and emotion-processing strategies are two types of coping strategies. The former refers to issue-solving procedures, whereas the latter refers to methods through which an individual regulates his or her emotional response to a problem scenario. Emotion-focused coping techniques are more likely to be used in cases of chronic stress and schizophrenia. Identifying and resolving such coping strategies might assist the doctor in tailoring cognitive strategies [21, 43].

Healthy coping methods like as self-control, accepting responsibility, and planned problem-solving were found to be much more prevalent during the early stages of the illness. This represents how younger schizophrenia patients adapt and cope with their circumstances. Those who have been demonstrated to have greater QOL are more likely to be employed and earning [22]. In our study, patients with advanced illness, on the other hand, tended to avoid or flee settings. This suggests that cognitive therapies aimed at increasing self-efficacy and social support are likely to improve patients' psychological wellbeing. Rehabilitation programs may be able to help with this.

Culturally, younger people, particularly men, are expected to work in order for their families to survive. As a result, younger patients were seen to exhibit positive coping abilities such as taking duties and problem-solving planning. Folsom et al. 2009 discovered that elderly patients had higher mental health QOL. It is critical that these patients commit to treatment in order to improve such positive coping abilities.

This study does have some drawbacks. This is a crosssectional study from a single center with a limited sample size. This cannot be applied to the entire Asian or national population.

\section{Conclusions}

The ability to cope with distress substantially contributes to the quality of life in the patients.

The supportive and psychoeducation strategies, coping skill training, rehabilitation programs, and cognitive-behavioral therapy focused to manage psychotic symptoms, enhance self-efficacy, and decrease distress could help patients to employ more adaptive coping strategies and improve their quality of life. 


\section{Abbreviations}

QOL: Quality of life; WHO: World Health Organization; ICD: International Classification of Diseases; WCC: Ways of Coping Checklist; DUI: Duration of illness; PSS: Perceived Stress Scale; IQ: Interquartile.

\section{Acknowledgements}

The authors are highly thankful to all the authors whose manuscripts have been consulted during this study. Gratitude to all the patients who gave consent to be part of this study.

\section{Authors' contributions}

SS: conceptualization, formal analysis, methodology, writing —original draft, data curation, validation, Visualization, investigation, project administration, resources, supervision, writing-review and editing. SD, AKG, and TS: conceptualization, formal analysis, methodology, writing —original draft, data curation, validation, visualization. SMS: conceptualization, data curation, formal analysis, methodology, writing — review and editing, investigation, project administration, resources, supervision. The authors read and approved the final manuscript.

\section{Funding}

Nil

\section{Declarations}

\section{Ethics approval and consent to participate}

All ethical considerations related to scientific research in humans have been taken into account in accordance with the Declaration of Helsinki [44]. Written consent was obtained from all participants in the current study; also, the research ethics committee at the Government T.D Medical College, Alappuzha, approved to conduct the current research dated [2012-15].

\section{Consent for publication}

The consent for publication has been given by all the authors who contributed in the study.

\section{Competing interests}

The authors declare that there are no competing interests.

\section{Author details \\ ${ }^{1}$ JLNM Hospital, J\&K, Srinagar, India. ${ }^{2}$ RMH \& NWMH, Melbourne, Australia. ${ }^{3}$ National Medical College, Birgunj, Nepal. ${ }^{4}$ International Islamic University, Islamabad, Pakistan. ${ }^{5}$ Independent Health Consultant, J\&K, Srinagar, India.}

Received: 22 August 2021 Accepted: 13 October 2021

Published online: 29 November 2021

\section{References}

1. Read J, Haslam N, Sayce L, Davies E (2006) Prejudice and schizophrenia: a review of the 'mental illness is an illness like any other' approach. Acta Psychiatr Scand 114(5):303-318. https://doi.org/10.1111/j.1600-0447. 2006.00824.x

2. Emsley R, Rabinowitz J, Medori R, Early Psychosis Global Working Group (2007) Remission in early psychosis: rates, predictors, and clinical and functional outcome correlates. Schizophr Res 89(1-3):129-139. https:// doi.org/10.1016/j.schres.2006.09.013

3. Tarbox SI, Addington J, Cadenhead KS et al (2014) Functional development in clinical high risk youth: prediction of schizophrenia versus other psychotic disorders. Psychiatry Res 215(1):52-60. https://doi.org/10. 1016/j.psychres.2013.10.006

4. Fan X, Henderson DC, Nguyen DD et al (2008) Posttraumatic stress disorder, cognitive function and quality of life in patients with schizophrenia. Psychiatry Res 159(1-2):140-146. https://doi.org/10.1016/j.psychres.2007. 10.012

5. Ciudad A, Alvarez E, Bobes J, San L, Polavieja P, Gilaberte I (2009) Remission in schizophrenia: results from a 1-year follow-up observational study. Schizophr Res 108(1-3):214-222. https://doi.org/10.1016/j.schres.2008.12. 004
6. Andreasen NC, Carpenter WT Jr, Kane JM, Lasser RA, Marder SR, Weinberger DR (2005) Remission in schizophrenia: proposed criteria and rationale for consensus. Am J Psychiatry 162(3):441-449. https://doi.org/ 10.1176/appi.ajp.162.3.441

7. Lasser RA, Nasrallah H, Helldin L et al (2007) Remission in schizophrenia: applying recent consensus criteria to refine the concept. Schizophr Res 96(1-3):223-231. https://doi.org/10.1016/j.schres.2007.05.003

8. Bodén R, Sundström J, Lindström E, Lindström L (2009) Association between symptomatic remission and functional outcome in first-episode schizophrenia. Schizophr Res 107(2-3):232-237. https://doi.org/10.1016/j. schres.2008.10.004

9. van Os J, Drukker M, Campo J, Meijer J, Bak M, Delespaul P (2006) Validation of remission criteria for schizophrenia. Am J Psychiatry 163(11):20002002. https://doi.org/10.1176/ajp.2006.163.11.2000

10. Wunderink L, Nienhuis FJ, Sytema S, Wiersma D (2007) Predictive validity of proposed remission criteria in first-episode schizophrenic patients responding to antipsychotics. Schizophr Bull 33(3):792-796. https://doi. org/10.1093/schbul/sbl015

11. Lysaker PH, Tsai J, Hammoud K, Davis LW (2009) Patterns of coping preference among persons with schizophrenia: associations with self-esteem, hope, symptoms and function. Int J Behav Consult Ther 5(2):192-208

12. Singh $G$, Sharan $P$, Kulhara $P$ (2002) Coping with hallucinations in schizophrenia: a correlational study. Hong Kong J Psychiatry 12(3):5-11+23

13. Wilder-Willis KE, Shear PK, Steffen JJ, Borkin J (2002) The relationship between cognitive dysfunction and coping abilities in schizophrenia. Schizophr Res 55(3):259-267. https://doi.org/10.1016/s0920-9964(01) 00211-0

14. Shah R, Grover S, Kulhara P (2017) Coping in residual schizophrenia: re-analysis of ways of coping checklist. Indian J Med Res 145(6):786-795. https://doi.org/10.4103/ijmr.IJMR_1927_14

15. Raguram R (1993) An exploratory study of coping styles in schizophrenic patients. Indian J Psychiatry 35(1):22-26

16. Shah R, Kulhara P, Grover S, Kumar S, Malhotra R, Tyagi S (2011) Relationship between spirituality/religiousness and coping in patients with residual schizophrenia. Qual Life Res 20(7):1053-1060. https://doi.org/10. 1007/s11136-010-9839-6

17. Hofstetter JR, Lysaker PH, Mayeda AR (2005) Quality of sleep in patients with schizophrenia is associated with quality of life and coping. BMC Psychiatry 5(1):13Available from. https://doi.org/10.1186/1471-244X-5-13

18. Hsiao CY, Hsieh MH, Tseng CJ, Chien SH, Chang CC (2012) Quality of life of individuals with schizophrenia living in the community: relationship to socio-demographic, clinical and psychosocial characteristics. J Clin Nurs 21(15-16):2367-2376

19. Gaite L, Vuzquez-Barquero JL, Borra C, Ballesteros J, Schene A, Welcher B, Thornicroft G, Becker T, Ruggeri M, Group the ES (2002) Quality of life in patients with schizophrenia in five European countries: the EPSILON study. Acta Psychiatr Scand 2002 105:283-292

20. Lambert M, Naber D (2004) Current issues in schizophrenia: overview of patient acceptability, functioning capacity and quality of life. CNS Drugs 18(Suppl 2):5-43. https://doi.org/10.2165/00023210-200418002-00002

21. Ritsner MS, Gibel A, Ponizovsky AM, Shinkarenko E, Ratner Y, Kurs R (2006) Coping patterns as a valid presentation of the diversity of coping responses in schizophrenia patients. In: Ritsner MS (ed) Sha'ar Menashe Mental Health CenterPsychiatry research, vol 144. Elsevier Science, Hadera, pp 139-152

22. Cai C, Yu L (2017) Quality of life in patients with schizophrenia in China: relationships among demographic characteristics, psychosocial variables, and symptom severity. J Psychosoc Nurs Ment Health Serv 55(8):48-54

23. Holubova M, Prasko J, Matousek S et al (2016) Comparison of self-stigma and quality of life in patients with depressive disorders and schizophrenia spectrum disorders - a cross-sectional study. Neuropsychiatr Dis Treat 12:3021-3030Published 2016 Nov 24. https://doi.org/10.2147/NDT.S1215 56

24. Skantze K, Malm U, Dencker S, May P, Corrigan P (1993) Comparison of quality of life with standard of living in schizophrenic patients. $\mathrm{Br} J$ Psychiatry 161:797-801

25. Lawrence R, Bradshaw T, Mairs H (2006) Group cognitive behavioural therapy for schizophrenia: a systematic review of the literature. J Psychiatr Ment Health Nurs 13(6):673-681

26. Wallwork RS, Fortgang R, Hashimoto R, Weinberger DR, Dickinson D (2012) Searching for a consensus five-factor model of the positive and 
negative syndrome scale for schizophrenia. Schizophr Res 137(1-3):246250. https://doi.org/10.1016/j.schres.2012.01.031

27. Morosini PL, Magliano L, Brambilla L, Ugolini S, Pioli R (2000) Development, reliability and acceptability of a new version of the DSM-IV social and occupational functioning assessment scale (SOFAS) to assess routine social functioning. Acta Psychiatr Scand 101(4):323-329

28. Mas-Expósito L, Amador-Campos JA, Gómez-Benito J, Lalucat-Jo L, Research Group on Severe Mental Disorder (2011) The World Health Organization quality of life scale brief version: a validation study in patients with schizophrenia. Qual Life Res 20(7):1079-1089. https://doi. org/10.1007/s11136-011-9847-1

29. Pargament KI, Koenig HG, Tarakeshwar N, Hahn J (2004) Religious coping methods as predictors of psychological, physical and spiritual outcomes among medically ill elderly patients: a two-year longitudinal study. J Health Psychol 9(6):713-730. https://doi.org/10.1177/1359105304045366

30. Cohen S, Kamarck T, Mermelstein R (1983) A global measure of perceived stress. J Health Soc Behav 24(4):385-396 Available from: http://www.jstor. org/stable/2136404

31. Lobana A, Mattoo SK, Basu D, Gupta N (2001) Quality of life in schizophrenia in India: comparison of three approaches. Acta Psychiatr Scand 104(1):51-55

32. Gupta S, Black DW, Arndt S, Hubbard WC, Andreasen NC (1998) Factors associated with suicide attempts among patients with schizophrenia. Psychiatr Serv 49(10):1353-1355Available from. https://doi.org/10.1176/ ps.49.10.1353

33. Grover S, Kate N (2014) How can we avoid delay in referrals of patients with delirium? Indian J Psychiatry [Internet] 56(3):309-310 Available from: https://www.indianjpsychiatry.org/article.asp?issn=0019-5545

34. Chandrasekaran R, Sivaprakash B, Jayestri SR (2002) Coping startegies of the relatives of schizophrenic patients. Indian J Psychiatry 44(1):9-13

35. Kate N, Grover S, Kulhara P, Nehra R (2014) Relationship of quality of life with coping and burden in primary caregivers of patients with schizophrenia. Int J Soc Psychiatry 60(2):107-116. https://doi.org/10.1177/00207 64012467598

36. Nehra R, Chakrabarti S, Kulhara P, Sharma R (2005) Caregiver-coping in bipolar disorder and schizophrenia. Soc Psychiatry Psychiatr 40(4):329336. https://doi.org/10.1007/s00127-005-0884-3
37. Sum G, Ho SH, Lim ZZB, Chay J, Ginting ML, Tsao MA et al (2021) Impact of a patient-centered medical home demonstration on quality of life and patient activation for older adults with complex needs in Singapore. BMC Geriatr 21(1):1-11

38. Correll C, Schooler N (2020) Negative Symptoms in Schizophrenia: A Review and Clinical Guide for Recognition, Assessment, and Treatment. Neuropsychiatr Dis Treat 16:519-34

39. Choo CC, PKH C, Ho CS, Ho RC (2017) Prediction of quality of life in asian patients with schizophrenia: a cross-sectional pilot study. Frontiers Psych 8:198 Available from: https://www.frontiersin.org/article/10.3389/fpsyt. 2017.00198

40. Sharma R, Dixit M, Verma S (2017) Directorate of education. Dir Educ Delhi, Delhi

41. Ortega L, Montalvo I, Monseny R, Vilella E, Labad J (2019) Perceived stress mediates the relationship between social adaptation and quality of life in individuals at ultra high risk of psychosis. Early Interv Psychiatry 13(6):1447-1454. https://doi.org/10.1111/eip.12791

42. Yang AC, Tsai SJ (2017) New targets for schizophrenia treatment beyond the dopamine hypothesis. Int J Mol Sci 18(8):1689Published 2017 Aug 3. https://doi.org/10.3390/ijms18081689

43. Bechdolf A, Klosterkötter J, Hambrecht M, Knost B, Kuntermann C, Schiller $S$ et al (2003) Determinants of subjective quality of life in post acute patients with schizophrenia. Eur Arch Psychiatry Clin Neurosci 253(5):228-235

44. World Medical Association (2018) WMA declaration of HELSINKI - ethical principles for medical research involving human subjects https://www. wma.net/policies-post/wma-declaration-of-helsinki-ethical-principlesfor-medicalresearch-involving-human-subjects/

\section{Publisher's Note}

Springer Nature remains neutral with regard to jurisdictional claims in published maps and institutional affiliations.

\section{Submit your manuscript to a SpringerOpen ${ }^{\circ}$ journal and benefit from:}

- Convenient online submission

- Rigorous peer review

- Open access: articles freely available online

- High visibility within the field

- Retaining the copyright to your article

Submit your next manuscript at $\boldsymbol{\nabla}$ springeropen.com 